A R T I G O

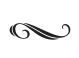

\title{
UM OLHAR SOBRE O AMANHÁ DA SAÚDE BRASILEIRA
}

\author{
Josier Marques Vilar
}

a Médico e Presidente do Fórum Inovação Saúde, E-mail: josier@ibkl.com.br

\section{RESUMO}

$\mathrm{O}$ artigo trata dos desafios, dilemas e paradoxos da saúde brasileira, enfatizando a necessidade de utilização das modernas ferramentas tecnológicas, da inovação na gestão e da inteligência artificial com seus algoritmos para superar a barreira do acesso ao cuidado e a universalidade do direito a serviços de saúde por todos os brasileiros, conforme determina a Constituição Federal. O texto dá ênfase à qualificação e importância da formação e capacitação de bons profissionais de saúde como fundamento básico para a estruturação de serviços médicos que contribuam para a qualidade de vida da populaçáo.

\section{Palavras-chave}

Governança, Gestão, Regulação, Modelos Assistenciais, Financiamento, Pesquisa, Inovação, Empreendedorismo, Educação e Desenvolvimento Industrial na Saúde.

\begin{abstract}
The article deals with the challenges, dilemmas and paradoxes of Brazilian health, emphasizing the need of using use modern technological tools, innovation in management and artificial intelligence with its algorithms to overcome the barrier of access to care and the universality of the right to health services by all Brazilians, as determined by the Federal Constitution. The text underlines the qualification and importance of training and qualification of good health professionals as a basic foundation for structuring medical services that contribute to the quality of life of the population.
\end{abstract}

\section{Keywords}

Governance, Management, Regulation, Assistance Models, Research, Financing, Innovation, Enterpreneurship, Education and Industrial Development in Health. 
Diz um ditado africano que "todos os dias de manhã, na África, o antílope desperta. Ele sabe que terá de correr mais rápido que o mais RÁPIDO dos leôes, para não ser morto. Todos os dias, pela manhã, na África, desperta o leão. Ele sabe que terá de correr mais rápido que o antílope mais LENTO, para não morrer de fome".

$\mathrm{O}$ mundo e em especial a medicina, tem sofrido modificaçóes numa velocidade jamais prevista pelos mais ousados sábios da era pós-moderna.

Os algoritmos e a inteligência artificial nos conduzem a lugares e espaços que jamais imaginamos. Ainda assim, permanecem muitas resistências às necessárias mudanças em nosso modelo de governança e de gestáo na saúde. O grande risco - para todos os que resistem a aceitar que o mundo digital, a nanoparticula e os algoritmos e blockchain chegaram para ficar - é que se transformem no antílope mais lento, e tenham o fim absolutamente previsível.

Assim, podemos afirmar sem medo de errar, que o modelo atual de governança e gestão da saúde não é sustentável do ponto de vista econômico, social, ambiental e moral.

Precisamos agir rapidamente, criando um sistema unificado de saúde que contemple o público e o privado como complementares e colaborativos, que possam garantir o compartilhamento seguro das informações médicas, o acesso universal e a integrali- dade do cuidado à toda população brasileira, utilizando para isso as modernas tecnologias de investigação diagnóstica e de orientação terapêutica.

É fundamental também que as universidades brasileiras se empenhem para formar novos profissionais para a gestáo de uma nova realidade sanitária, com o olhar da segurança operacional com qualidade assistencial e custo controlado, e que sejam capacitados do ponto de vista comportamental para o exercício pleno de suas atividades. $\mathrm{O}$ treinamento e a capacitação dos milhares de profissionais de saúde já em atividade no país, permitindo a eles que se adequem às demandas da atualidade, reduzirá os desperdícios de vidas, de recursos financeiros e de autoestima, que hoje verificamos em boa parte dos nossos profissionais.

Mas também é de responsabilidade das organizaçóes de saúde que compóem a cadeia produtiva do setor, fomentar a capacitação de seus profissionais, mantendo-os permanentemente atualizados e alinhados com o tempo inovador que todos vivemos.

Para que o setor avance, é necessário que a sociedade brasileira possa perceber, com toda a clareza, como ficou demonstrado durante a epidemia de Covid19 que estamos vivemos, que um bom sistema de saúde é fundamental para garantir a segurança de toda a populaçáo, e que investimentos humanos e financeiros compatíveis com essa expectativa necessitam ser adequadamente feitos. 
Políticas públicas que garantam a qualificação profissional, o acesso aos serviços de saúde e a integralidade de cuidados deveria fazer parte do compromisso social do Estado brasileiro.

Repensar o modelo da saúde brasileira, focando em açôes básicas de saúde e utilizando as modernas ferramentas de gestão da informação, incluindo as análises preditivas através de inteligência artificial e seus algoritmos, que utilizam big datas como fonte de suas informaçóes, pode ser o melhor caminho para garantirmos uma qualidade assistencial compatível com as melhores práticas de medicina em todo o mundo.

Até porque, montamos nossa estrutura assistencial para o tratamento das doenças agudas e o nosso problema maior hoje são as doenças crônicas, que atingem mais de $1 / 3$ da população mundial.

Além da Covid, que demonstrou nossa fragilidade para o enfrentamento das doenças agudas, vivemos uma "epidemia" de doenças crônicas, e nossos sistemas de informaçáo para a saúde estão totalmente desconectados e despreparados para esse enfrentamento, tanto no setor público como no privado.

Deveríamos já, adotar a Declaração de Asgtana, sucessora da Declaração de Alma Ata, onde os países subscritores comprometeram-se fundamentalmente em construir cuidados de saúde primários sustentáveis, capacitar indivíduos e comunidades ali- nhando o apoio das partes interessadas às politicas, estratégias e planos nacionais.

Isso, foi tudo o que não vimos durante essa trágica pandemia de Covid19 que estamos vivendo, onde inexistiram planos e estratégias de abrangência nacional e coordenação integrada entre todas as esferas.

Aprender com os erros que cometemos agora e no passado, e construir um modelo de gestáo integral da saúde, do nascimento até a morte, será o grande desafio para a década que se inicia.

Não podemos perder mais uma oportunidade de aprendizado que a natureza nos concedeu e a ciência respondeu com brilhantismo e à velocidade necessária.

Para que avancemos mais, teremos de utilizar a tecnologia, a ciência e a inovação a favor das pessoas. Desenvolver bases de dados confiáveis, seguras, obedecendo a nova lei geral da proteçáo de dados, com coleta, análise, compartilhamento e execução do ato médico de forma segura, moralmente aceitável e eticamente correta é tudo que a população brasileira espera de nós profissionais da saúde.

$\mathrm{Ou}$ inovamos, ou o modelo atual desaparecerá, levando consigo as mentes resistentes. Agora é a hora de mentes intrépidas e inovadoras, sem jamais esquecermos que bons serviços de saúde são fundamentais para a qualidade de vida de uma população, mas bons serviços de saúde somente existem 
com bons profissionais de saúde, afinal, governança, gestão, financiamento, tecnologia e inovação são necessários, mas pessoas, sempre elas é que fazem toda a diferença.

Cada vez mais a sociedade se torna exigente em relação aos serviços em geral em aos serviços de saúde em particular.

Se queremos ser reconhecidos como objeto de desejo de toda a população pela qualidade do serviço que prestamos, temos de ter foco na entrega de valor para o paciente. Isto é o que chamamos de ROE (Retorno sobre a experiência). É isto que agrega valor ao nosso serviço.

Portanto, nossa prioridade de investimentos e de acolhimento, deveria ser sempre nas pessoas, do recepcionista, do paciente ao médico ou pesquisador, afinal, são elas, e não os mármores que garantirão a sustentabilidade de nossas instituições.

\section{Conclusão}

Para garantir a sustentabilidade do setor saúde, torna-se necessário valorizar e investir na qualificação técnica e comportamental de todos os agentes de saúde, com a mesma ou maior intensidade que se valoriza os investimentos em tecnologias, processos e resultados operacionais.

\section{Conflito DE INTERESSE}

O autor declara não ter nenhum conflito de interesse

\section{LITERATURA SUGERIDA}

1. "21 liçoes para o século 21" - Yuval Noah Harari - Editora Companhia das Letras

2. "A Física do Futuro" Michio Kaku Editora Doubleday 